\title{
Charity Care: Do Nonprofit Hospitals Give More than For-Profit Hospitals?
}

J Gen Intern Med 36(10):3279-80

DOI: $10.1007 / \mathrm{s} 11606-020-06147-9$

(c) Society of General Internal Medicine 2020

\section{INTRODUCTION}

There is debate as to whether nonprofit hospitals in the USA provide sufficient benefit to their communities to warrant their tax exemption status, ${ }^{1}$ an exemption previously valued at $\$ 24.6$ billion nationally. ${ }^{2}$ Despite the Affordable Care Act (ACA) reforms, there has been minimal change in community benefit spending by nonprofit hospitals, especially in the form of charity care. ${ }^{3}$ Charity care refers to unbilled and uncollected expenses that the hospital provides for patients unable to pay for services.

While several studies have evaluated the amount and value of charity care provided by nonprofit hospitals or have compared charitable spending in a specific state, recent research comparing charity care across similar for-profit and nonprofit hospitals nationally is lacking. ${ }^{4-6}$ In this study, we matched for-profit hospitals to nonprofit hospitals that share the same size, location, and teaching status, and compared charitable spending relative to total expenses.

\section{METHODS}

We used the 2018 Medicare cost reports published by the Centers for Medicare \& Medicaid Services, which is the most recent full year of data publicly available. The Medicare cost report includes data on hospital characteristics and utilization, as well as hospital charity care costs and total hospital expenses. All continuous measures were winsorized at the 95th and 5th percentiles. We matched for-profit hospitals to nonprofit hospitals on teaching hospital status, geographical region (West, South, Midwest, and Northeast), and bed size group ( $<100$ beds, $100-349$ beds, and $>349$ beds).

Our primary outcome was charitable spending as percent of total expenses for for-profit and nonprofit hospitals, consistent with other studies which standardize charitable spending. ${ }^{3,4}$ We tested the difference between nonprofit hospitals and forprofit hospitals by using a linear mixed-effects model with charity care as percent of total expenses as the outcome and hospital ownership status as the independent variable with

Received July 11, 2020

Revised July 11, 2020

Accepted August 12, 2020

Published online September 1, 2020 random intercepts for the matched group to allow for correlation between hospitals within matches. We then stratified the analysis by hospital size.

Using data on median household income by zip code from the Dartmouth Atlas, we mapped each hospital to the average median household income for the hospital's zip code. We then performed stratified analyses by median household income.

\section{RESULTS}

Average total charity care was $\$ 4.3 \mathrm{M}$ for for-profit hospitals and $\$ 7.1 \mathrm{M}$ for nonprofit hospitals. We present results in Table 1 using charity care as percent of total expenses. The overall mean for charity care as percent of total expenses was $2.62 \%$ for for-profit hospitals compared with $2.95 \%$ for

Table 1 Charity Care as Percent of Total Expenses by Size

\begin{tabular}{|c|c|c|c|c|}
\hline & $\begin{array}{l}\text { For-profit } \\
\text { hospitals }\end{array}$ & $\begin{array}{l}\text { Nonprofit } \\
\text { hospitals }\end{array}$ & $\begin{array}{l}\text { Difference } \\
\text { (95\% CI) }\end{array}$ & $P$ value \\
\hline & $\begin{array}{l}\text { Mean } \\
\text { charity } \\
\text { care } \\
\text { as percent } \\
\text { of total } \\
\text { expenses } \\
(n=725)^{*}\end{array}$ & $\begin{array}{l}\text { Mean } \\
\text { charity care } \\
\text { as percent } \\
\text { of total } \\
\text { expenses ( } n \\
=\mathbf{2 0 6 8})^{\dagger}\end{array}$ & & \\
\hline Overall & $2.62 \%$ & $2.95 \%$ & \multirow{4}{*}{$\begin{array}{l}0.34 \% \\
(-0.29 \%, \\
0.96 \%) \\
1.24 \% \\
(0.60 \%, \\
1.87 \%) \\
0.11 \% \\
(-1.03 \%, \\
1.21 \%) \\
-1.11 \% \\
(-1.93 \%,- \\
0.32 \%)\end{array}$} & 0.29 \\
\hline $\begin{array}{l}\text { Small } \\
\text { hospitals }\end{array}$ & $1.81 \%$ & $3.05 \%$ & & $\begin{array}{l}P< \\
0.001 * *\end{array}$ \\
\hline $\begin{array}{l}\text { Medium } \\
\text { hospitals }\end{array}$ & $2.96 \%$ & $3.06 \%$ & & 0.85 \\
\hline $\begin{array}{l}\text { Large } \\
\text { hospitals }\end{array}$ & $3.72 \%$ & $2.60 \%$ & & $0.007 * *$ \\
\hline
\end{tabular}

For-profit hospitals were matched to nonprofit hospitals on teaching hospital status, geographical region (West, South, Midwest, and Northeast), and size. Hospitals with total beds under 100 were classified as small-sized hospitals, hospitals with total beds 100-349 were classified as medium-sized hospitals, and hospitals with 350 beds or greater were classified as large-sized hospitals. Estimates were calculated using a linear mixed-effects model with charity care as percent of total expenses as the outcome and ownership status as the independent variable with random intercepts for the matched group to allow for correlation within matches.

$* P<.05, * * P<.01$

*Among for-profit hospitals, there were 318 small-sized hospitals, 338 medium-sized hospitals, and 69 large-sized hospitals.

†Among nonprofit hospitals, there were 564 small-sized hospitals, 1,042 medium-sized hospitals, and 462 large-sized hospitals. 
Table 2 Charity Care as Percent of Total Expenses by Median Household Income for the Hospital Location

\begin{tabular}{|c|c|c|c|c|}
\hline & \multirow{2}{*}{$\begin{array}{l}\text { For-profit hospitals } \\
\text { Mean charity care as percent of total } \\
\text { expenses }(n=725)^{*}\end{array}$} & \multirow{2}{*}{$\begin{array}{l}\text { Nonprofit hospitals } \\
\text { Mean charity care as percent of total } \\
\text { expenses }(n=2068)^{\dagger}\end{array}$} & \multirow[t]{2}{*}{ Difference (95\% CI) } & \multirow{2}{*}{$\begin{array}{l}P \\
\text { value }\end{array}$} \\
\hline & & & & \\
\hline $\begin{array}{l}\text { Low-income } \\
\text { locations }\end{array}$ & $2.95 \%$ & $2.65 \%$ & $\begin{array}{l}-0.30 \%(-1.16 \% \\
0.53 \%)\end{array}$ & 0.48 \\
\hline $\begin{array}{l}\text { Middle-income } \\
\text { locations }\end{array}$ & $2.61 \%$ & $3.22 \%$ & $\begin{array}{l}0.61 \%(-0.21 \% \\
1.42 \%)\end{array}$ & 0.14 \\
\hline $\begin{array}{l}\text { High-income } \\
\text { locations }\end{array}$ & $2.16 \%$ & $2.09 \%$ & $\begin{array}{l}-0.062 \%(-0.73 \% \\
0.60 \%)\end{array}$ & 0.85 \\
\hline
\end{tabular}

For-profit hospitals were matched to nonprofit hospitals on teaching hospital status, geographical region (West, South, Midwest, and Northeast), and size. Hospitals serving regions with median household income under $\$ 30,000$ were classified as low income, hospitals serving regions with median household income between \$30,000 and \$79,999 were classified as middle income, and hospitals serving regions with median household income above $\$ 79,999$ were classified as high income. Estimates were calculated using a linear mixed-effects model with charity care as percent of total expenses as the outcome and ownership status as the independent variable with random intercepts for the matched group to allow for correlation within matches. *Among for-profit hospitals, there were 88 low-income hospitals, 552 middle-income hospitals, and 85 high-income hospitals.

†Among nonprofit hospitals, there were 326 low-income hospitals, 1,487-middle income hospitals, and 255 high-income hospitals.

nonprofit hospitals, a non-significant difference of $0.34 \%$ $(95 \% \mathrm{CI}-0.29,0.96 ; P=0.29)$.

Among small-sized hospitals, the mean charity care as percent of total expenses for for-profit hospitals was $1.81 \%$ compared with $3.05 \%$ for nonprofit hospitals, a statistically significant difference of $1.24 \%$ (95\% CI $0.60,1.87 ; P<$ $0.001)$. There was no statistically significant difference in charity care as percent of total expenses between mediumsized for-profit and nonprofit hospitals. Among large-sized hospitals, the mean for charity care as percent of total expenses for for-profit hospitals was $3.72 \%$ compared with $2.60 \%$ for nonprofit hospitals, a statistically significant difference of $1.11 \%(95 \% \mathrm{CI}-1.93,-0.32 ; P=0.007)$.

When stratified by median household income of each hospital's zip code, we observed no statistically significant differences in charity care as percent of total expenses (Table 2).

\section{DISCUSSION}

While the average for-profit hospitals spent less in total charity care than nonprofit hospitals, there was no significant difference between for-profit and nonprofit hospitals in charity care as percent of total expenses. When stratified by size, small forprofit hospitals spent less than small nonprofit hospitals while large for-profit hospitals spent more than large nonprofit hospitals.

We found no differences in charity care as percent of total expenses between for-profit and nonprofit hospitals located in lower-income zip codes, middle-income zip codes, or higher income zip codes.

Medicare cost reports are subject to data errors. Additionally, charity care is only one community benefit that nonprofit hospitals perform. Still, our analysis demonstrates that nonprofit hospitals may not be providing the level of charity care warranted by their tax exemption status, and in some cases may be spending relatively less than their for-profit counterparts.
Joseph D. Bruch, B. A. ${ }^{1}$

David Bellamy, B. A. ${ }^{2}$

${ }^{1}$ Department of Social and Behavioral Sciences, Harvard T.H. Chan School of Public Health, Boston, MA, USA

${ }^{2}$ Department of Epidemiology, Harvard T.H. Chan School of Public Health,

Boston, MA, USA

Corresponding Author: Joseph D. Bruch, B. A.; Department of Social and Behavioral Sciences, Harvard T.H. Chan School of Public Health, Boston, MA, USA (e-mail: Jbruch@g.harvard).

Data Availability Reproducible Research Statement: Study protocol: Not available. Statistical code: Available from Joseph Dov Bruch (e-mail, jbruch@g.harvard.edu). Data set: Available from Joseph Dov Bruch.

\section{Compliance with Ethical Standards:}

Conflict of Interest: The authors declare that there is no conflict of interest.

\section{REFERENCES}

1. Herring B, Gaskin D, Zare H, Anderson G. Comparing the value of nonprofit hospitals' tax exemption to their community benefits. INQUIRY: The Journal of Health Care Organization, Provision, and Financing. 2018;55:0046958017751970.

2. Rosenbaum S, Kindig DA, Bao J, Byrnes MK, O'Laughlin C. The value of the nonprofit hospital tax exemption was \$24.6 billion in 2011. Health Affairs. 2015;34(7):1225-33.

3. Young GJ, Flaherty S, Zepeda ED, Singh SR, Rosen Cramer G. Community benefit spending by tax-exempt hospitals changed little after ACA. Health Affairs. 2018;37(1):121-4.

4. Young GJ, Chou CH, Alexander J, Lee SYD, Raver E. Provision of Community Benefits by Tax-Exempt U.S. Hospitals. New England Journal of Medicine. 2013;368(16): 1519-27.

5. Bai G, Yehia F, Anderson GF. Charity Care Provision by US Nonprofit Hospitals. JAMA Internal Medicine. 2020;180(4):606-7.

6. Song PH, Lee SYD, Alexander JA, Seiber EE. Hospital ownership and community benefit: looking beyond uncompensated care. Journal of Healthcare Management. 2013;58(2):126-41.

Publisher's Note: Springer Nature remains neutral with regard to jurisdictional claims in published maps and institutional affiliations. 